\title{
Colaboran en este número
}

Raul Avila

Es profesor en la Facultad de Derecho y Ciencias Sociales de la Universidad Nacional de Córdoba. (Argentina).

\section{José Cano}

Es licenciado en Derecho por la Universidad de Barcelona y profesor ayudante del Departamento de Sociología de la Universidad Autónoma. Actualmente trabaja en su tesis doctoral: «Clase y Partido».

\section{José LuTS CRESPÁN}

Es alumno de sociología en la Universidad Autónoma de Barcelona.

\section{Amando de Miguel}

Es doctor en Ciencias Políticas por la Universidad de Madrid y realizó estudios de postgrado en Sociología en la Universidad de Columbia de Nueva York. $\mathrm{Ha}$ dirigido también los conocidos Informes sociológicos sobre la situación social de España de la Fundación FOESSA. Actualmente es Catedrático contratado de la Universidad Autónoma de Barcelona.

\section{JuAN Estruc $\mathrm{H}$}

Es licenciado en Filosofía y Letras y doctor en Sociología de las Universidades de Barcelona y Lovaina. Especializado en Sociología 
de la Religión, es autor de varios libros y artículos sobre el tema. Es actualmente profesor agregado de la Universidad Autónoma de Barcelona.

\section{Juan F. Marsal}

Es doctor en Derecho por la Universidad de Barcelona y en Sociología por la Universidad de Princeton. Tiene varios libros publicados, entre ellos: Cambio Social en América Latina y Los Intelectuales políticos. Es actualmente profesor en las Universidades Autónoma de Barcelona y del Salvador de Buenos Aires.

\section{Benjamín Oltra}

Se licenció en Ciencias Políticas en la Universidad de Madrid. Ha colaborado en diversas investigaciones empíricas sobre la estructura social de España. Actualmente es profesor adjunto en la Universidad Autónoma de Barcelona. Trabaja en su tesis sobre «Intelectuales españoles».

\section{Esteban Pinilla de las Heras}

Está diplomado en Ciencias Económicas y Sociales por la Ecole Pratique de París, donde actualmente es Chef de Travaux en el Centre d'Etudes des Mouvements Sociaux, del que es director el Prof. Alain Touraine. Es autor, entre otras obras, de L'empresari catala y Reacción y revolución en una sociedad industrial.

\section{JuAN SALCEDO}

Está actualmente acabando sus estudios de licenciatura en la Universidad Autónoma de Madrid. Es coautor del libro Dinámica del desarrollo industrial de las regiones españolas.

\section{Antonio Tulla}

Es licenciado en Ciencias Económicas de la Universidad de Barcelona y profesor ayudante en la Facultad de Letras de la Universidad Autónoma. Está especializado en Sociología Rural.

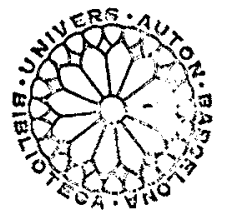

